\title{
Streptococcus gordonii
}

National Cancer Institute

\section{Source}

National Cancer Institute. Streptococcus gordonii. NCI Thesaurus. Code C86792.

A species of facultatively anaerobic, Gram positive, cocci shaped bacteria in the phylum Firmicutes. This species is positive for alpha hemolysis, beta glucosidase, beta glucuronidase, esculin hydrolysis and arg inine deaminase, and negative for catalase and urease. It can ferment amyg dalin, inulin, galactose, salicin, cellobiose, maltose, lactose, sucrose, and trehalose but not mannitol, sorbitol, melibiose or raffinose. S. gordonii is found in normal human oral flora but can be a pathogen causing dental caries, gum disease and endocarditis after oral trauma. 